\title{
Sovasova and the Problem of Sameness: Converging Interpretive Frameworks for Making Sense of HIV and AIDS in the Trobriand Islands
}

\author{
Katherine Lepani \\ Australian National University
}

\begin{abstract}
This article considers how different models of sexuality and disease converge and interact to co-produce understandings of HIV and AIDS, and the implications of inter-cultural communication for effective HIV prevention in diverse settings. In the Trobriands Islands of Papua New Guinea, the phenomenon of sovasova, or chronic illness that manifests when members of the same matrilineal clan have sexual relations, is a persuasive and problematic form of cultural knowledge that directly influences comprehensions of HIV and AIDS. As a social proscription, sovasova underscores cultural ideations about the importance of social exchange and the corporeal mixing of difference in sexual relationships. Trobrianders recognize clear signs and symptoms that herald the onset of sovasova, which are similar to descriptions of AIDS-related illness-weight loss, nausea, and malaise. Affected people use various herbal and magical treatments to effectively manage sovasova, and people can avoid the sickness altogether by simply not having sex with a fellow clan member. The cultural resources available for treatment allow people to regard transgression as a safe possibility, albeit socially undesirable. The broad comparisons that Trobrianders draw between sovasova and AIDS create tensions as people contemplate HIV prevention based on the cultural model of sexual disorder and the valued capacity and efficacy of sexuality in maintaining relations of difference.
\end{abstract}

Key words: sexuality, illness, kinship, epidemiology, HIV/AIDS, Papua New Guinea.

\section{INTRODUCTION}

This kind of sexual behaviour [having multiple partners] is part of our custom so it is not really surprising to us about AIDS, because maybe we already know this disease through sovasova. Because we have the clan system and we follow it in our sexual behaviour and if we don't follow it we get sick. So maybe people from other places don't understand about the clan system and they have too much mixing of the same kind and that is how this virus has spread and made so many people sick. But here we know this sickness and we have treatment. We can control the spread.

Trobriand man, aged mid-30s, 4/11/03

HIV is far greater than a microscopic pathogen. The human immunodeficiency virus 'transcends the boundaries of biomedicine' (Huber and Gillapsy 1998:191) as it moves through cultural landscapes and becomes visible in the social body, configured by discourses of sex- 
uality, morality, fear, risk, and disease, and the meanings people bring to bear on the information they receive. Concurrent with the persistent spread of HIV infection throughout the world is the proliferation of multiple ways of comprehending HIV and AIDS as different knowledge systems and discourses converge and interact, producing an 'epidemic of meanings or signification' (Treichler 1999:11).

The migration of predominantly western models and moralities about disease causality, sexuality, and sexual behaviour has enormous influence on the interpretive process of making sense of HIV and AIDS in diverse cultural contexts. The application of external models of meaning potentially affects the capacity for people to articulate and clarify local understandings and form cognitive links with new information. The discursive production of HIV and AIDS is able to rupture deep layers of cultural knowledge and expose established forms of meaningful practice to new evaluations. For example, Philip W. Setel's ethnography of the epidemic in Northern Tanzania demonstrates how 'the disordering effects of the epidemic are simultaneously creative of new meanings and revealing of long-standing values which surround social reproduction' (1999:16). The discursive production of meanings also underscores how perceptions and understandings of HIV and AIDS change over time as experience of living with the effects of the epidemic unfolds (Farmer 1990, 1992). Additionally, the question of temporality has a direct bearing on eliciting perceptions through the process of research, as Paul Farmer (1992:287) points out: 'Investigation of evolving understandings of AIDS calls attention to the problems inherent in studying cultural meaning while it is taking shape.'

Drawing on ethnographic fieldwork in the Trobriand Islands of Milne Bay Province, Papua New Guinea, this article examines the discursive dimension of the epidemic, and the dialogical mediations between a specific cultural model of sexuality and disease and received representations of HIV and AIDS.' The views presented are a representative sample of the perspectives of adolescent and adult men and women obtained during unstructured interviews, group discussions, and informal conversations. While mindful that 'the way the epidemic is brought to people's attention will be the critical determinant of how they will respond to it' (Reid 1994:1), my concern here is how an existing cultural model provides an interpretive framework for making sense of new phenomena. The popular abstraction of AIDS as a looming threat from beyond the islands provides a pivotal reference for the assertion of Trobriand ideations of sexuality, morality, and disease. The Trobriand concept of sovasova, or chronic illness that manifests from the breach of clan exogamy when members of the same matrilineal clan have sexual relations, is a persuasive and problematic form of cultural knowledge that directly influences comprehensions of HIV and AIDS in the Trobriand context. The topic of sovasova emerged unprompted in nearly every scheduled interview session held during the research. The consistent association people draw between sovasova and AIDS reflects a logical attempt to resolve the uncertainty about the presence of HIV in the Trobriands, and temper the seemingly paradoxical representation of AIDS as a new disease of sexual risk that has no available treatment or cure. That an introduced and novel disease has no treatment or cure is antithetical to the traditional model of medicine, and contradicts popular notions of modern biomedicine as well, commonly perceived as having a diagnostic regimen of drug treatment for every known disease.

I begin with a brief overview of the factors influencing how the presence of HIV and AIDS is taking shape in the Trobriands. I then distill some of the germane elements of Trobriand ideology on kinship, exchange relations, and sexuality to provide a conceptual framework for considering the significance of sovasova in maintaining relations of difference. Then I present a description of sovasova and offer a comparative analysis of sovasova and HIV and AIDS to consider points of convergence and distinction, and to look specifically at how Trobrianders' conceptual engagement with HIV and AIDS is mediated by cultural knowledge and social practice. Finally, I discuss the implications of cultural representations of sexuality and illness for effective responses to the challenges of a localised HIV epidemic in the Trobriands. 


\title{
THE PRESENCE OF HIV IN THE TROBRIANDS
}

\begin{abstract}
When we got the awareness, we are all afraid of AIDS, so we are asking, do you have any ideas to help us see this thing, to help us with our feeling about AIDS, to help us understand about AIDS so we won't be afraid?
\end{abstract}

Trobriand woman, aged mid-50s, Kaituvi Village, 19/9/03

The presence of HIV in the Trobriands, with a population of nearly 30,000 people, remains largely abstract, made known primarily through how people are talking about the virus and the syndrome. To date, few Trobrianders have direct experience with the clinical and social manifestations of diagnosed HIV sero-positivity. Estimations of the number of people living with HIV in the Trobriands are highly speculative, as is the case in most rural and remote areas of Papua New Guinea, due to limited primary health services and diagnostic resources, and the unavailability of HIV voluntary counselling and testing services. There are several non-confirmed cases of people returning home to the Trobriands after having tested HIV-antibody positive in urban centres, and a few anecdotal reports of people dying from HIV-related illness. AIDS is speculated to be the probable cause of death in a number of instances, especially if the deceased suffered prolonged, degenerative illness after having travelled or resided outside the islands. In 2001, the first case of confirmed HIV was reported by the Losuia District Health Centre on Kiriwina (the main island in the Trobriand group) after serum testing was conducted at the Central Public Health Laboratory in Port Moresby. The district Health Extension Officer (HEO) ordered the test after the patient failed to respond to drug treatment for diagnosed tuberculosis. The HEO called this the 'first home-grown case' because the patient had never travelled outside Kiriwina (T. Elliot, HEO, pers. comm.).

The conundrum of HIV visibility holds the challenge of soliciting preventive action before the presence of the virus becomes evident in a way that compels an immediate response. Yet the presence of factors associated with HIV susceptibility suggests that the Trobriands potentially faces a critically serious epidemic unless prevention efforts are comprehensively put into place. These factors include early onset of sexual activity; frequent acquisition of new sexual partners including concurrent partners; high prevalence of sexually transmitted infections (STI); ${ }^{4}$ and low levels of condom use. Further social and economic factors compound HIV susceptibility, including increased mobility between the Trobriands and urban centres; intensified commercial trade networks through maritime travel; limited income earning opportunities within the local economy; and greater population pressure on a finite resource base.

Not withstanding the indeterminacy of HIV prevalence in the Trobriand population, the discursive presence of the epidemic is palpable. Talk about HIV and AIDS has gained prominence in local discourse about contemporary concerns and issues, and communication about HIV risk and prevention has become increasingly common through various community-based awareness activities, training workshops, and through informal flows and exchange of information. Increased political and media attention on the escalating epidemic in PNG, and various awareness campaigns orchestrated at the national and provincial levels, have significant influence on how HIV and AIDS are represented and discussed at the local level. Awareness information modelled on biomedicine and epidemiology carries moralistic interpretations, amplified by an amalgamation of Christian and traditional cosmological beliefs. Throughout the country, including the Trobriands, churches provide the main organisational framework for facilitating HIV and AIDS awareness training at the community level, with variable results in terms of the willingness to address sexual practice and the use of condoms for protection against viral transmission (Luker 2004:5, 10). The popular discourse of AIDS persistently represents HIV infection in terms of sexual deviance and 
excess, a bias reinforced by the epidemiological categories of 'risk groups' and 'risk behaviours.' Fear of death pervades the tone of communication and incites responses of stigma, shame, and blame as people struggle to comprehend a sickness that has no available treatment or known cure.

In contrast to areas in PNG where moralistic reactions to the epidemic thwart communication about sexuality, sexual behaviour, and HIV prevention (Eves 2003; Hammar 2005), the topic of HIV and AIDS has been largely received in the Trobriands with candid interest. People express a collective concern to overcome the fear of the unknown and address the implications of an impending epidemic. I suggest this response is due in part to perduring Trobriand cosmology, which values sexuality as consensual and pleasurable practice that sustains the flows of reciprocity between clans, maintaining the relations of difference that activate social reproduction. Christian doctrine has not generated a repressive attitude to sexuality nor has it supplanted traditional ideals of sexuality. The existing cultural vocabulary facilitates the capacity to talk about sex and sexual relations and to contemplate interconnections between sexual practice and disease etiology.

Yet the spectre of AIDS as a 'killer disease' wrought by sexual deviance and excess holds tensions and contradictions in relation to the Trobriand model of sexuality and disease. The received discourse of HIV and AIDS persistently aligns sex with deviance, disease, and death, while largely ignoring the dimensions of sexual desire, consensus, and pleasure. The standard 'ABC' prevention model frames sexuality in terms of 'risk' and 'promiscuity,' and promotes a moral hierarchy of behaviour change, where 'abstinence' and 'being faithful' is preferable to condom use. Trobriand mediations of HIV prevention involve reconciling the fear of sickness and death, and the behaviours attributed to HIV transmission and infection, with sexual practices that are culturally valued as life-affirming, consensual, and pleasurable acts that build and reinforce social relations. In particular contention is the question of whether sovasova is analogous to AIDS and therefore provides an existing moral guide for modifying sexual behaviour associated with the transmission of disease.

\section{THE SAMENESS OF SUBSTANCE AND THE MIXING OF DIFFERENCE}

In order to consider how the cultural model of sovasova has a conceptual bearing on Trobriand mediations of HIV and AIDS, it is helpful to first review some basic elements of Trobriand social reproduction that uphold the principle of reciprocal relations of difference. The Trobriand social universe comprises four ranked exogamous matrilineal clans, or kumila, known by name as Malasi, Lukuba, Lukwasisiga, and Lukulabuta. Every Trobriand person belongs to one of the four clans as well as one of numerous sub-clans or lineages, called dala, which are the main units of social identity and economic exchange (Malinowski 1929:417; Weiner 1976:51). Together kumila and dala identity comprise the incontrovertible substance of personhood, which transcends corporeal life and regenerates at conception through matrilineal ancestral spirits, or baloma. Veyola, or the 'sameness of substance' (Malinowski 1929:422), is the general term for clansperson, or 'people like us,' as opposed to 'people different from us,' referred to as tomakava (Weiner 1976:52-54). The suggestion in the opening statement above that 'maybe people from other places don't understand about the clan system' is indicative of the presumed universality of the Trobriand clan system, with the fourfold division of humanity applicable to all human communities, whether people are cognisant of it or not."

The process of reproduction through conception, gestation, and birth (and indeed, throughout the life cycle) is socially viable when investments of nurture and material support for matrilineal substance are channelled through exchange relations with tomakava, established through conjugal partnerships and through children's relational ties to their father's dala. Weiner (1979:332-333) explains the reproductive process as having two complementary components: 
[O]ne accommodates the reproduction of dala identity (achieved through women and ancestral substance), while the other simultaneously augments dala by the continual accumulation of outside resources (initially the contributions a man makes to the growth of a foetus). In this way, the autonomy of dala is tempered by the incorporations of outside resources through dependency on 'others' who are members of different dala.

The cultivation of yams for exchange is the core of the Trobriand subsistence economy and provides the 'symbol par excellence of the reproductiveness of social relations' (Weiner 1979:333). Yams are redistributed between kumila and dala through extensive social networks that reinforce intergenerational and exogamous relations through familial ties between sons and fathers, fathers and daughters, and brothers and sisters' spouses (Weiner 1976:137-153). Underpinning the exchange relations formed by yam distributions are the large-scale mortuary exchange feasts, called sagali, which take place immediately after a death and then again after a period of mourning that formally lasts between six to twelve months. Constituting the basis for the reproduction of social relations and the regeneration of matrilineal identity, the work of sagali compels people to invest dala resources in social and economic relationships with non-kin (Weiner 1976, 1980b). The primary value accorded to the maintenance of relations of difference and the regeneration of matrilineal identity through sagali transactions is viewed as a significant measure of the historical stability and resilience of Trobriand society in interaction with the effects of modernity (see Jolly 1992; Weiner 1980b). The key role performed by Trobriand women in sagali transactions exemplifies their strong social and economic position. Trobriand women possess a potent sense of autonomy and control in the expression of their sexual and reproductive agency and they speak with assuredness about their regenerative power to 'grow' their dala to be strong for sagali (Lepani 2001:56). Bidalasi, the active verb for reproductive agency, derives from the core concept of matrilineal source and substance.

The optimal flow of resources between different dala occurs through intergenerational exchange relations between veyola, which are established and reinforced through relations with nonclanspeople. These pivotal connective relationships, called keyawa, are achieved primarily through marriage and affinal ties, particularly when sons marry into their father's clan, and daughters marry into the clan of their maternal uncle's wife, which ideally is their own father's clan as well. The ideal marriage partner for a young man is his father's sister's daughter; likewise, the ideal spouse for a young woman is her mother's brother's son. The pool of suitable partners, respectively, includes the offspring of parents' classificatory siblings (Malinowski 1929:86; Weiner 1976:53). My informants told me that the term kaytabu$l a$, a contraction of the word for sexual intercourse (kayta) and the kinship category tabu," signifies the ideal sexual partner and potential spouse, and the means for reconnecting members of the same clan through pivotal affinal exchange relations. The kaytabula partnership represents what Trobrianders call a 'criss-cross' strategy for reinforcing affinal exchange ties and ensuring that dala resources stay between two lineages linked by tabu relations (Lepani 2001:59). Weiner reports that both men and women laughingly told her this strategy was a 'trick' because marrying tabu serves as a link for creating 'significant and long-term exchange relationships with members of one's own clan' (1976:53).

Kaytabula reflects the premium placed on the corporeal mixing of difference in heterosexual partnering and suggests how sexuality is regarded as a productive resource to build and reinforce exchange relations between people of different clans and lineages, and to create keyawa relationships with one's own clan members. The commencement of sexual activity is valued as a critical transition in the physical and social development of a young person, activating the potential capacity for social reproduction. Young people enjoy considerable sexual freedom before marriage, rehearsing their future economic roles as married adults by forging the potential alliances that will sustain the relations of social reproduction. 
The collective Trobriand term for unmarried male and female youth, kubukwabuya, also means 'freedom.' Ulatile and kapugula are the gendered terms for sexually active unmarried men and women, respectively, which describe both the subject and the act of being mobile in pursuit of sexual liaisons. Youth sexuality embodies the autonomy to pursue one's desire, to attract the desire of others, and to trial successive partners for potential conjugality.

That sexual relations incorporate the value of exchange is expressed by buwala, or the requisite gifts of betel nut, tobacco, clothing, or cash, which men give their sexual partners after love-making, and which women anticipate as a respectful gesture of protocol and a symbol of mutual pleasure. Buwala is evidence of a young woman's ability to attract partners, and it indicates the 'fitness' of a potential husband to help grow the woman's dala and expand the relational network between clans. The importance of mutuality is reflected also in the term bilamapula, which describes the physically responsive movement between partners during sexual intercourse that results in orgasm, when semen and vaginal fluids, both referred to by the single term momona, effect the corporeal mixing of difference (Malinowski 1929:285). The transactional dynamics of Trobriand sexuality find similar expression in Tubetube Island, also in Milne Bay, as noted by Martha Macintyre (1987:213):

Sexuality is rarely spoken of in terms of dominance and submission. Sexual intercourse epitomizes equal, balanced exchange and is one metaphor used when alluding to a perfectly matched transaction where valuables of equal rank are exchanged between partners of equal renown. Seduction is the art of persuasion and agreement, not conquest and surrender.

However, consent and mutuality are not without contestation in the exercise of personal desire. Both men and women use love magic, or kwaiwaga ${ }^{8}$ to demonstrate their power to seduce and attract potential partners, and to cause the chosen partner to be overcome by 'love.' The use of kwaiwaga is the primary means to secure fidelity and pave the way for the bond of marriage. In this way, the efficacy of kwaiwaga shifts the pleasures of intimate sociality from the private domain of desire into public purview, where sexual alliances are subjected to the larger social networks within which they operate (Weiner 1988:71, 1992:76).

The intimacy of a sexual encounter invariably extends beyond the union of two bodies and ultimately represents the relationality between two clans. For this reason, the strict decorum of concealment, or katupwana, retains the autonomy of youth sexuality and prevents activation of the social obligations that commence when a relationship is formally recognised. Young people take great care to hide their sexual liaisons from public view until they enter into a steady partnership and seek endorsement from their respective families. Specifically, a young woman conceals her sexual relations from her father, who represents the key social link to another dala-a link that takes on new significance through marriage, when a sexual relationship is transformed into a publicly acknowledged inter-clan exchange relationship. Of fundamental importance for both males and females is the concealment of their sexual activity from cross-sex siblings by strict adherence to avoidance taboos. Young girls in particular take extreme care not to be seen by their brothers, or to see them, when they are with their respective sexual partners. Avoidance between cross-sex siblings is related to the 'supreme taboo' of sovasova, which prohibits 'any erotic dealings... between brother and sister,' and by extension, between any male and female of the same dala or kumila (Malinowski 1929: 437). Characterised by Malinowski as the 'most important and most dramatic feature of the Trobriand social organisation' (1929:451), deeply ingrained in the collective psyche, the sovasova taboo is an 'inviolable law' of primeval ordination, 'tokunabogwa ayguri' [of old it was ordained] (1929:389). 


\section{SOVASOVA AND THE PROBLEM OF SAMENESS}

Sovasova occurs from sexual intercourse when the same blood or same clan recognises itself. The same blood cannot mix properly, it is neutralised, and so germs can grow inside the people who are affected. Sexual fluids carry clan 'signatures,' maybe a bit like DNA. If two people with the same clan blood have sex, the sexual fluids do not mix and germs are able to grow.

Lester Bisibisera, Provincial Disease Control Officer, Alotau, 9/4/03

When same clan has sex, sovasova is passed through blood or genes, in English you might say chromosomes. Because they are the same clan the blood cannot mix, so sickness will result. Sickness forms inside like a tumor or thickness. There is no direction either way, it just gets stuck and doesn't move.

Traditional healer, Mulosaida village, 16/10/03

Custom is very, very important on Trobriand Islands. Through custom become realities. Belief becomes reality. Maybe there is no sickness there but as we believe, that sickness passes between same clan, from one to another through sexual fluid, it passes both ways.

Ethel Jacob, Kwemtula village, 23/9/03

The term sovasova ${ }^{10}$ refers both to the fundamental proscription against intra-clan sexual relations and marriage between cross-sex siblings, real and classificatory, and to the ethnophysiological ailment that results from the breach of the exogamy taboo. Social theory on the universality of the incest taboo suggests that the taboo has a 'social network-building function,' and 'exists to promote the broad networks of social relations and economic exchange that are constitutive of the social world' (Meigs and Barlow 2002:39). The Trobriand phenomenon of sovasova highlights the relationality of sexual practice, which holds the potential for regeneration through the corporeal mixing of substances of difference, producing and reinforcing important social ties and exchange relations. Sovasova etiology is concerned with two levels of causality - the origin or underlying cause, and the immediate cause that commences the pathological process (see Foster 1976:778; Ingstad 1990:32). Fundamental to the underlying cause of sovasova is the breach of exogamy, which threatens social order and the basis for social reproduction through established patterns of exchange. The immediate cause of sovasova is sexual intercourse between two people of the same clan. Sovasova is a cultural model that "links sickness to moral concerns and social relations' (Farmer 1990:23). The dual meaning of sovasova and the two levels of causality illustrate the metaphoric connection between bodily experience and social and moral order, and how 'individual pathologies are homologous with social pathologies' (Sobo 1993:54).

Descriptions and explanations of sovasova follow a consistent schema but vary according to people's knowledge, experience, and ability to draw analogies with other knowledge systems, particularly biomedicine, as evidenced in the statements above. Consistent in all descriptions is the emphasis on the problem of sameness of substance, when sexual intercourse between members of the same clan fails to be socially and physically productive because the 'signature' sexual fluids of the clan are unable to promote the reciprocal flow and mixing of difference. The Trobriand homology between social and physical flow and good health is consistent with other models of disease etiology found in societies that place high value on reciprocal exchange as the basis for creating social networks and collective health (Sobo 1993:54; Taylor 1988:1348).

The 'neutralisation' of sameness, which results in internal congestion or stagnation, provides the ideal conditions for the growth of germs or worm-like parasites (minumauna, 
or maunauwela), which have chronic debilitating effects on the host. The illness of sovaso$v a$ has discernible signs and symptoms, kabotuvatusi, including severe stomach pain, abdominal swelling, 'dusty' skin, pallor, boils, wasting, and malaise. Descriptions suggest that the illness may affect one partner more than the other depending on their general state of health prior to the breach. There is disagreement as to whether sovasova diminishes reproductive capacity and the viability of offspring born to parents of the same clan. Some explanations hold that babies are born sickly and die prematurely. Sovasova is treatable with a combined regime of botanical and magical remedies, called kelawodila (literally, 'trees of the forest'), which purge the minumauna out of the body and restore healthy bodily flow. The specialised knowledge of treatment is highly valued, safeguarded within lineages, and obtained from either dala members or specialist healers, called toyuvisa (literally, 'man who untangles'). Treatment allows sovasova to be managed like a chronic illness. As one person explained in a group discussion, "The parasites or virus of sovasova get together from the relationship so that's why we have the sickness. So we would definitely have the treatment if we are having sex with someone from the same clan."

In practice, while the rule of exogamy between dala is strictly adhered to, exogamy between kumila is flexible, often breached in casual sexual encounters and occasionally breached through marriage (Malinowski 1929:432; Weiner 1988:74). Because of the availability of treatment, people regard the breach of kumila exogamy as a safe possibility, albeit socially undesirable. People are willing to breach the taboo for casual relations, believing that illness only becomes a chronic problem in steady and long-term relationships or marriage. 'If they keep on going to that person for quite a number of times then that's where sovasova comes in. If only one night, then, so, it doesn't come in as a risk. People won't really worry about sovasova if it is only one night., ${ }^{12}$ Some people speak of using the treatment like a 'morning after' prophylactic to prevent the onset of illness resulting from casual one-off encounters between fellow clan members.

In his various accounts of sovasova, Malinowski treated with particular relish the willingness of people to breach the taboo as evidence of the 'complex currents and undercurrents which form the true course of tribal life' (1929:433). ${ }^{13}$ Noting that the supreme taboo falls away with the gradual classificatory extension of the brother-sister relationship, Malinowski imputed that the breach is regarded in various degrees as 'daring and dangerous, but not abominable' (1929:443-444); 'a desirable and interesting form of erotic experience' (1929:430); 'a thing both smart and desirable, owing to the piquant difficulties in carrying it out' (1953:96); 'and a spicy, not very repressed prohibition' (1953:97). Malinowski observed, with a distinctly masculinist tinge, "The moral shame of such incidents is in reality small, and as with many other rules of official morality, he who breaks it is a smart fellow' (1953:99). He further acknowledged that the prophylactic magic for sovasova is 'absolutely efficacious' (1953:99), and 'well-nigh universally known and is used very freely' (1929:431).

Because sovasova illness is the inevitable outcome of violating the incest taboo, prevention is relatively straightforward to negotiate, simply by disclosing clan identity to a potential sexual partner and choosing not to engage in sexual relations if both parties are of the same clan. People do not construct sovasova in terms of taking a chance with an unknown outcome. The following excerpt from an interview with a married woman, aged early $40 \mathrm{~s}$, indicates the protocol involved in negotiating sexual encounters to avoid partnering with someone of the same clan.

My mother gave me advice about sovasova in grade five. I heard people talking about it and was scared of it. It is a continuous sickness unless we have strong medicine. I have seen people suffering. I saw it with my eyes; OK, it is true. It is only through carelessness, that's how they get involved with this sickness, sovasova. We ask, 'Avaka kumila yokwa? What clan are you?' 'Oh, sorry, my brother!', if 
he is same clan. And we go our separate ways.

(And do you feel shame if he is your brother?)

No, not if we don't know each other, say if we are from different villages. But mostly, young people take care who they go with. They send messages, use messengers to plan the meetings, so they know before who is the right partner for them.

There is broad and irrefutable consensus that witchcraft, yoyowa, and sorcery, bwagau or bogau, do not factor in the cause or consequence of sovasova, although people acknowledge that those affected by the illness are more vulnerable to the exploits of witches and sorcerers. The most powerful reason for people's willingness to engage in sexual relations with a fellow clan member is love. The source of desire for someone of the same clan is attributed most often to love magic, reflecting the mythic origin of the incest taboo which tells of a brother and sister who die in each other's arms after coupling on the beach, overcome by the power of love magic (Malinowski 1929:456-459). There is also a popular narrative that speaks of love unencumbered by the use of kwaiwaga, where people's strong feelings of love empower them to reject the taboo of sovasova, if not the ethnophysiological consequence of illness. As one toyuvisa explained to me, "In the past, sovasova was very taboo but in present times people don't care. The mentality about sovasova is changing, because of love. People are accepting that they can have this sickness if they really love each other.' ${ }^{\text {is }}$

Although a popular idiom to describe sovasova is 'STI between same clan,' people maintain a cognitive distinction between sovasova and pokesa, the general term derived from the English word 'pox' used to describe STIs that involve genital ulcers or discharge, including syphilis, donovanosis, and gonorrhoea. Underscoring the distinction is the belief that, unlike sovasova, sorcery and witchcraft can be the cause of pokesa.

Pokesa is different from sovasova, it is a sore on the outside. People usually go to the health centre for pokesa. They recognise it as a disease they can get medicine for. ${ }^{16}$

Pokesa is different. We know it is gonorrhoea. Some people use magic to make people get this one. Because we have certain people in the village having this magic, so we must look around for someone who can cure it. If we go to the hospital, OK, they can help, tablets can help. But most of the time our people, old people, have certain herbs for it."

Given the Trobriands' history of public health interventions for sexually transmitted diseases, perhaps it is perplexing why the cultural model of pokesa is not readily brought to bear on mediations of HIV and AIDS. I suggest that the causal and physiological distinctions made between sovasova and pokesa transect with the moralistic renderings of AIDS as a novel, deadly disease caused by transgressive sexual behaviour, which has no immediate visible manifestations and no cure. Similar to representations of AIDS, sovasova is an internalised chronic ailment aligned with a heavy moralistic narrative. The word pokesa refers to the visible signs and symptoms of sexually transmitted infections, which can be treated and healed. However, while pokesa is generally accepted as a possible consequence of sexual activity, it is not regarded as symptomatic of deviant sexual practice. The cause of pokesa is most often explained as the discontent of malevolent agents of witchcraft and sorcery.

Below is an extended excerpt from an interview with the HEO at Losuia District Health Centre, which illustrates the influence of different interpretive frameworks in Trobriand articulations of sovasova etiology, and how people make diagnostic comparisons with other disease symptoms, in particular the symptoms of other known sexually transmitted infections. 
As for people's understanding of HIV/AIDS, you would know about sovasova, believed to be from a sexual relationship between same clan members. I have to bring this into my awareness talks because people have the question in their minds. When people reach old age or have some illness, people tend to say the sickness is because they were with their own clan members, that's why they have those symptoms. Pain, weakness, weight loss. You could say it was just old age. On the health side, I regard it as UTI, PID presentation (urinary tract infection and pelvic inflammatory disease). On clinical grounds, this is how I see the sickness of sovasova. As for the belief, there are four major clans and many dala. So for example, if a Malasi man sleeps with a Malasi woman then in the long run they will have sovasova. It is applicable to all clans. As a clinician, I don't take into account sovasova management. Because of beliefs and thoughts already in place, people still take it as sovasova. It's a traditional belief, that same clan and opposite sex, during the sex act, the release and exchange of fluids from both men and women during the penile ejaculation and female orgasm. Because the fluids exchanged are from the same clan members, that's why there is sovasova. It can affect young people but most often comes out in old age. If a young person is sick they will take it as sovasova. For example, malaria symptoms, they will still consider it as sovasova if they know that they have had sex with same clan. The idea is very vague. It is passed on from generation to generation. It is hard to explain anatomical composition of fluids in the body. There is no clinical documentation of this sickness. But for transmission, it is not like a disease going from one person to another, no, but it is about exchange, the mixture when the fluids come together. Absorption is taking place. The male absorbs the female, the female absorbs the male. To me personally, I can't explain here what happens between members of different clans. Let's say it is an exchange of difference. Mixing of difference. With sovasova, there is nothing different to exchange. The man and woman manage sovasova in the traditional way. Other times, if the problem is so significant, the person cannot contain it with the traditional system so they run to the health centre. They might see then that the symptoms can be treated with a mixture of ideas. It is a misconception with sexually transmitted infections and urinary tract infections. Some people come to realise that sovasova is really pelvic inflammatory disease and UTIs. Before when donovanosis and syphilis were very common, people were able to know the difference between gonorrhea and syphilis and sovasova. There is a distinct difference between ulcerated STIs and sovasova. People can recognise pokesa, or genital ulcers. But not all would come to the health centre for treatment. It is the level of literacy. Some resort to the traditional methods. They take it as the normal thing. Not all sickness is treated. Some who have symptoms take it for granted and once the sore goes away they think the sickness is gone. 18

My question that elicited the HEO's statement asked for his views on Trobrianders' perceptions of HIV and AIDS. The immediate reference he makes to the conundrum of sovasova in relation to HIV and AIDS indicates the conceptual association that people invariably make between the uniquely Trobriand phenomena and the new and unknown sickness. The HEO's comment that the symptoms of sovasova 'can be treated with a mixture of ideas' is indicative of pluralistic understandings of illness and how the complementary application of different models of therapy might assist in obtaining desired outcomes. Indeed, it could be argued that this pluralism reflects a conceptual preference for models of reciprocity, a preference that emanates from the core cultural value of mutual difference in achieving collective well-being. Speaking as a health professional, the HEO was understandably concerned that his comments reflect a clinical interpretation of sovasova. Yet the 
enduring cultural logic of sovasova is apparent in his explanation. This underscores the importance of approaches to HIV communication that acknowledge how divergent models of meaning interact and shape new understandings. The facilitation of dialogical mediations between preexisting models of disease and information about HIV and AIDS as new disease phenomena is critical for producing new knowledge that will enable prevention.

\section{CONVERGING FRAMEWORKS: SOVASOVA COMPARED WITH HIV AND AIDS}

People tend to think that HIV/AIDS is not necessarily a new problem but has been around for a long time, just called something else, sovasova.

Lester Bisibisera, Alotau, 9/4/03

Some people say we already have the cure for the disease HIV/AIDS because it has been here a long time; we already have this sickness sovasova.

Ethel Jacob, 20/6/03

We were told that some Trobriand people, who live in Alotau and Port Moresby, who have the sovasova treatment, have given it to people who are sick with AIDS. For that, I don't believe it, that it would work. Because I know that AIDS has a different virus and sovasova has a different maunauwela.

United Church pastor, Kuruvitu village, 13/11/03

Documenting the emergence of a collective representation of AIDS in rural Haiti, Farmer (1990:20, 22) illustrates how the "'adoption" of a new illness category into an older interpretive framework' provides 'organising principles' and 'preexisting meaning structures' for people's shifting understandings and experience of the new disorder as the HIV epidemic develops in a particular setting. Although the broad comparisons that Trobrianders draw between sovasova and representations of HIV and AIDS pose contradictions and create tensions, the preexisting interpretive framework holds significant influence in mediations of new information. Trobrianders comprehend HIV infection and prevention in relation to their cultural model of sexual disorder and the valued capacity and efficacy of sexuality and sexual networks in maintaining relations of difference.

Representations of both sovasova and HIV are conceptually associated with behaviour that deviates from normative moral and sexual codes. However, there is evident dissonance in the values of sexuality represented by the two models of disease etiology. The organising principles in the sovasova paradigm that link disease with unproductive sex between spiritual and corporeal sameness do not readily accommodate representations of HIV as caused by sexual promiscuity and infidelity. The extended period of multiple partnering and casual sexual encounters that define kubukwabuya sexuality is valued as life-affirming social practice, and is definitely not associated with disease and death.

There is a dissimilarity as well in conceptualisations of disease transmission and, hence, disease prevention. The violation of sexual taboo does not spread infection from one body to another in an asymmetrical direction; rather, disease is generated between two bodies of sameness as the result of unproductive sexuality. Preventing sovasova is as straightforward as declaring clan identity, unless people are overcome by the power of kwaiwaga or desire. Most awareness information about HIV infection is constructed around the notion of transmission from one body to another, so that infection is generally conceptualised as a singular event involving a unidirectional source of infection. Communication about HIV transmission and prevention invariably raises questions about the relative invisibility of HIV before the effects of infection become apparent in a human host, and how confirmation 
of HIV antibody status is not possible without blood testing. The time lapse between cause and effect does not easily support a conceptual link between sexual practice and HIV infection, nor does it readily compel immediate action to minimise and prevent potential transmission.

Information about the use of condoms as the barrier means of protection against HIV transmission, especially as protective of the male bodies on which they are placed, tends to reinforce perceptions that the source of viral infection is contained within bodies marked by epidemiological categories of risk, in particular, female bodies. The globalised language of HIV prevention has inscribed condoms with risk and danger, their use associated with promiscuity, infidelity, and high-risk behaviour, symbolising distrust in sexual relationships rather than negotiated consent (Bujra 2000). The association between condoms and risk is commonly reiterated in PNG, with the consequence that protected sex is perceived as morally bad while unprotected sex is held to be morally good and assumed within marriage and other intimate relationships (Hammar 1998; but see Wilde, this collection, for how condoms are morally acceptable as a family planning method). To an important extent, the perception that HIV risk is something that exists beyond spatial boundaries of familiarity influences the use of condoms in the Trobriands, with young men reporting that because of limited availability and supply they reserve condoms for use with sexual partners from outside their immediate network of relationships.

The question of whether condom use can prevent the effects of sovasova between bodies of sameness poses a particular conundrum regarding the desirability of flow and mixture of sexual fluids as opposed to the admixture of sameness, which results in diseased stagnation. Because condoms as a contraceptive method are already associated with unproductive sexual contact, counteracting the desired mixing of difference, the proposition that condoms might work as a barrier method for sovasova seems redundant and counterintuitive to many people. Some of my informants said that condoms are 'wasteful things,' turning potent sexual fluids into rubbish to be discarded. Yet despite the apparent contradictions to desired effect, there is growing evidence that condoms are gaining acceptance in the Trobriands as the means to protect against HIV and STI transmission, and to prevent against unwanted pregnancy (see Keck, this collection, for similar positive attitudes towards condom use among young men and women in Yupno).

A further point of dissonance between the two models of disease etiology lies in the problematic question of HIV treatment, which is also counterintuitive to Trobriand notions of health and illness. The information people receive about HIV and AIDS consistently carries the misleading message of 'no treatment, no cure,' which instills fear and dread of the 'killer disease' with the tacit intention of stressing the importance of prevention through behaviour change. The representation of HIV and AIDS as having no treatment or cure compounds the uncertainty about the presence of HIV infection and its potential transmission between sexually active bodies, creating fear and ambivalence among Trobrianders. Yet the pre-existing interpretive framework helps mitigate the fear of the unknown through reference to a known phenomenon and the cultural resources for alleviating symptoms and managing sickness. The following statement made during a group discussion with women of mixed age and marital status reflects how the sovasova framework provides a pivotal point of reference for alleviating fear of the unknown.

The reason why we are afraid of AIDS is that we do not have any experience with it. We wonder what a person with AIDS feels like, looks like. We have no experience with the symptoms. It is hard to know because we can't tell who would have the sickness. We know people get the sickness but we don't know the symptoms because of the time it takes. Talking about fear, it is the same for sovasova, how we feel about AIDS is the same as sovasova. But with sovasova we have the treatment so we are not so afraid. We haven't tried sovasova treatment to see if it could 
work for HIV/AIDS because we don't know who might be sick with the virus. If someone we know has AIDS, then we could try the treatment to see if it works.

The issue of treatment is perhaps the most important area of concern in Trobriand mediations of AIDS. Although asymptomatic HIV infection is difficult for people to imagine, representations of 'full-blown AIDS' are immediately associated with the debilitating effects of sovasova: weight loss, pallor, malaise, and chronic illness. Consequently, there is a commonly shared perception that knowledge of sovasova treatment holds the potential means, if not the panacea, to mitigate the effects of AIDS. People speak with confidence about the efficacy of known herbal and magical treatments to manage sovasova and they speculate with varying degrees of confidence about the potential to treat the new sickness.

Some people feel that AIDS might be the same as sovasova. So they say we can use the same treatment for curing AIDS, this is what we feel, because we don't have any treatment for AIDS. I think, because AIDS, the symptoms are, well, slight difference from symptoms of sovasova. But I think if we use this medicine for sovasova to treat one of the AIDS carriers, I think it will help them.

Although people are quite clear that witchcraft and sorcery do not factor in the etiology of sovasova, unlike pokesa etiology, it is uncertain whether Trobrianders will attribute AIDS to witchcraft as more people confront the experience of living with the debilitating effects of HIV infection. As is the case throughout PNG, witchcraft and sorcery are powerful explanatory constructs in Trobriand cosmology that on some level hold an etiological link to all illness and misfortune. There is a strong tendency to attribute the immediate cause of any death to the malevolence of witches, who are reputed to target vulnerable bodies or people not duly circumspect about the potent jealousy of witches (Malinowski 1929:137; Weiner 1988:39-41). Because all illness and death are perceived as the loss of dala vitality, witchcraft and sorcery represent the ultimate threat to maintaining the relations of social reproduction and social order.

\section{IMPORTANCE OF CULTURAL MODELS FOR HIV PREVENTION}

Because of what we believe about sovasova it happens that way. United Church pastor, Kuruvitu village, 13/11/03

The Trobriand phenomenon of sovasova illustrates how the cultural construction of illness is symbolic of moral issues, social identity, and social relations (Pelto and Pelto 1997:150), and how diseases are 'cultural products given a specific moral lexicon depending on symptomology and the ideological needs of a society' (Craddock 2000:154). Furthermore, sovasova demonstrates the dynamic quality of cultural models and the ambiguities and inconsistencies that are inherent in all interpretive frameworks (Lewis 1993:212). The fluidity of explanation about a culturally specific illness like sovasova suggests that mediations of a new disease complex like HIV and AIDS are also likely to produce pluralistic interpretations. Nonetheless, as a persuasive paradigm for social and sexual relations in Trobriand society, sovasova provides an important pre-existing interpretive framework for integrating new information. This, of course, raises the broader question of the utility of diverse cultural models of sexuality and disease in HIV communication, and the consequences of converging interpretations for the prevention and management of HIV infection.

I suggest here several areas of consideration regarding the convergence of representations of sovasova and HIV and AIDS, and the significance they hold for communication about HIV prevention and management in the Trobriand context. Firstly, because most information about HIV infection is constructed around the notion of transmission from one 
body to another, HIV is commonly viewed as deriving from a single event and a unidirectional source of infection. This has implications for the extent to which the moral discourse surrounding the epidemic in PNG and elsewhere is negatively preoccupied with identifying and blaming the perceived source of infection. The etiological model of sovasova is significant for its emphasis on the interaction between bodies, and the recurring effect that every act of intercourse has on the course of the ailment. Sovasova is generated between two people of the same clan; it is not transmitted from one person to another. This feature of the model might contribute to a clarified understanding in the Trobriands of the importance of cross-infection and re-infection between bodies in the disease progression of HIV. Knowledge of this dimension of HIV transmission is important, especially in a context like PNG with a generalised epidemic, limited testing and condom use, and limited availability of treatment, not only for transforming sexual practice but also for potentially shifting negative attitudes towards categories of people perceived as responsible for spreading the virus.

Secondly, sovasova raises the fraught issues of fear, stigma, and blame surrounding HIV and AIDS, which have largely defined the collective response to the epidemic throughout Papua New Guinea. I suggest that the cultural vocabulary provided by the sovasova paradigm enables Trobrianders to discuss collectively the subject of HIV and AIDS with a confidence that alleviates negative and harmful reactions. While sovasova is a socially undesirable condition that carries a measure of shame, the breach of taboo does not produce reactions of discrimination or reproach. Because the breach represents the antithesis of productive social relations, and as such is an illogical and unproductive strategy, Trobrianders primarily regard sovasova violation as a matter of imprudent choice and conduct. The transgression concerns the internal dynamics of the clan and as such is not the concern of the larger community. Transgressors bear the consequences of chronic ill health and perhaps incur some mild gossip, but they have recourse to available treatment and the community does not ostracize them. Importantly, the power of love, whatever its source, can be appealed to rhetorically to legitimate relations of sameness. It remains to be seen whether the moral framework of sovasova might positively influence the tone of response in the Trobriands to people affected by HIV and AIDS. Nonetheless, the capacity to discuss candidly the interrelated topics of sexuality and disease opens channels for potentially engendering a measured and compassionate response to the challenges of the HIV epidemic. The mitigation of fear lessens the prospect that discrimination, stigma, and blame will define the response to HIV and AIDS as further direct experience with the epidemic in the Trobriands continues to shape people's collective understandings.

A third area of consideration is the importance of STIs as co-factors in HIV transmission. The cognitive distinction Trobrianders draw between sovasova and pokesa, or ulcerous STIs, is significant in terms of the treatment decisions people make. But the distinction is also problematic in that it may serve to over-emphasise the similarity people make between sovasova and AIDS, thereby detracting from the important etiological link between HIV and other sexually transmitted infections, particularly ulcerous STIs, which increase the possibility of HIV transmission. This is an important area to highlight in HIV communication in the Trobriands.

Perhaps the most significant area of consideration, given the resource constraints for an effective clinical response to HIV in the Trobriands, is the question of treatment. The beliefs and practice associated with the etiology of sovasova and its treatment have direct consequences for the way Trobrianders mediate information about HIV prevention and for decision-making regarding treatment options for HIV-related illness. The potential for traditional treatments to provide efficacious symptomatic treatment for AIDS-related illness bears serious consideration in the Trobriands, where antiretroviral therapies for HIV infection are neither currently available nor likely to be in the near future. Of course, this proposition raises ethical concerns about the use of alternative treatments for the management of HIVrelated illness, and the larger structural disparities and global inequities of resource distribu- 
tion that have tremendous bearing on the capacities of governments, communities, and people to effectively respond to the HIV epidemic. Regardless of whether herbal treatments for sovasova are pharmacologically efficacious from a biomedical point of view, if AIDS is conceptualised as similar to or the same as sovasova, the confidence about the capacity to deal with HIV infection through traditional methods of sovasova treatment may undermine HIV prevention efforts and encourage complacency about the potential impact of the epidemic.

Communication about HIV and AIDS invariably involves a process wherein different domains of knowledge converge and interact to co-produce meaning. Greater attention to the interpretive process of understanding HIV and AIDS is critically important for enabling the capacity for transformation. The moralistic tropes of risk and promiscuity that dominate the language of HIV prevention are not easily accommodated by Trobriand ideations of sexuality, which celebrate premarital sexual activity as healthy and life-affirming, and which stress the productive values of reciprocity and relations of difference. Encountering HIV prevention messages that construct sexuality in terms of risk and culpability may prompt resistance to such distancing rhetoric, or simply avoidance and disinterest, rather than promoting dialogical exchange of information and reflective evaluation of practice.

The Trobriand model of sexuality and disease provides a powerful illustration of how new information is mediated by established interpretive frameworks. The model implicitly critiques conventional public health understandings of what constitutes 'healthy' and 'risky' sexual behaviour, and calls to question the assumptions of standard HIV prevention messages. Indeed, the intrinsic values of reciprocal exchange and difference in Trobriand ideology are highly compatible to interactive processes of knowledge production, and make a potent argument for the fertile mixing of different ideas over a more diffuse model of pluralism. The Trobriands offers a strong case for HIV communication approaches that facilitate the dialogical engagement of local meanings for mediating new information. The process of exchange between different interpretive frameworks provides an important basis for identifying points of convergence, seeking clarification, and supporting comprehension towards the larger objective of HIV prevention and treatment.

\section{ACKNOWLEDGEMENTS}

I wish to express my appreciation and respect for the many Trobriand people who made this research possible. I am especially indebted to Diana Lepani Siyotama, Florence Mokolava, Ethel Jacob, and the late Asi Toyola for their commitment to the project and the valuable advice and support they gave me. Kagutoki kwaiveka. I wish to thank also an anonymous referee for constructive comments on this paper.

\section{NOTES}

1. My research explores how Trobrianders individually and collectively make sense of HIV and AIDS in relation to cultural knowledge and embodied experience of gender, sexuality, reproduction, health, and illness. I conducted initial fieldwork from December 2000 to January 2001, as part of the Master of Public Health program at the University of Queensland. My doctoral fieldwork was for a ten-month period in 2003 . I am grateful to UNICEF PNG for a research grant in 2000, the PNG National AIDS Council for a research grant in 2003, and scholarship support from the Gender Relations Centre, Research School of Pacific and Asian Studies, Australian National University.

2. Antiretroviral therapies are available in PNG only through a pilot program at a few selected health facilities and from a limited number of private medical practitioners. The contentious issue of HIV treatment availability is entangled with global policy issues concerning health inequities and resource constraints, as well as the capacity of the PNG health system to deliver treatment services and monitor treatment compliance.

3. There are 33 administrative wards, or census units, throughout the six coral atolls of the Trobriands, with a total of 92 villages, each comprised of residential clusters based on sub-clan groupings. Village populations range in size from 150 to 1000 inhabitants, with four villages having populations of approximately 1000 inhabitants.

4. The Trobriands has a long history of dealing with syphilis, gonorrhea, and donovanosis. In the late 19th and early 20th centuries, the colonial administrators and Christian missionaries sought to contain the spread of 
STIs by regulating and reforming what they perceived as undisciplined and immoral native bodies (Eves 1996; Reed 1997). In 1905, the Trobriands became the second site in the administrative Territory of Papua for the public health intervention program and treatment clinic for STIs, commenced by the colonial administration (Denoon 1989; Hughes 1997). Dr Bellamy, the resident medical officer from 1905 to 1916, "considered every native to be a suspect...concerning venereal disease,' and he aimed to examine every man, woman, and child in the Trobriands on an annual basis in order to maintain a venereal register (Black 1957:234).

5. See Malinowski (1929:416-417) and Weiner (1988:74) for accounts of similar expressions of the presumed universality of the Trobriand clan system.

6. The kinship term tabu is complex and holds multiple meanings, as expounded by Weiner (1979:339-340). Broadly, tabu refers to ancestral founders of dala; grandparents and grandchildren, reciprocally; father's sister, father's sister's husband, and father's sister's daughter; and from a female ego's standpoint, mother's brother's son and mother's brother's daughter. Tabu is not related to the notion of taboo, or bomala in Kiriwina language.

7. See Weiner (1980a) for a review of how the root word, mapula, has been rehearsed in the anthropological literature on exchange theory.

8. Malinowski concludes The Sexual Life of Savages with the transcription and exposition of the Kumilabwaga myth, an oral account of the origin of kwaiwaga, which Malinowski regards as the 'singular rift in traditional doctrine, a dogmatic inconsistency, which makes love and the magic of love derive from brother and sister incest' (1929:451). He explains that the myth 'establishes a valid precedent for the efficacy of love magic; it proves that the spells and rites... are so powerful that they can even break down the terrible barriers which separate brother and sister and persuade them to commit incest' (1929:459). Weiner suggests 'the myth is a celebration of sibling sexuality - the origin of love magic and the more hidden origin of matrilineal reproduction' (1992:76). She refers to the myth to make the theoretical claim that sibling intimacy is the basis of matrilineal power, suggesting that women are impregnated by ancestral kinsmen (1992:73-74; fn 22, 172), and that the elaborately ritualized intense sexuality that pervades so much of Trobriand adolescent life is another attempt, unsuccessful at the extreme, to disguise the power of sibling sexuality' (1992:fn 32, 173).

9. In contrast to the substantial ethnographic attention sovasova received from Malinowski, it seems anomalous that Weiner made no mention of sovasova by name or description in her ethnographic accounts (1976, 1979. 1980a, 1980b, 1988, 1992), especially as she focused her extensive interpretive analysis of Trobriand kinship ideology on the brother-sister relationship (see fn. 8 above).

10. Malinowski (1929) used the spelling 'suvosova.' I prefer the spelling used by my research participants, which best reflects the contemporary pronunciation of the word and is consistent with the orthography of Kiriwina language developed by linguist Ralph Lawton (1993).

11. Taped group discussion with women of mixed age and marital status, Kaituvi village, 19/9/03.

12. Taped interview with Ethel Jacob, research collaborator, 23/9/03.

13. Malinowski used sovasova as an analytical device to demonstrate the importance of participant observation fieldwork in unveiling cultural idealisations-'the polished surface of custom' (1929:426)—-to reveal contradictions in actual practice. He wrote, 'What I wish to make clear, by confronting the gist of native statements with the results of direct observation, is that there is a serious discrepancy between the two' $(1929: 425)$. In the section on 'Exogamy and the Prohibition of Incest' in The Sexual Life of Savages (1929:416-433), Malinowski launches into a lengthy methodological treatise on the inadequacy of the 'technique of question-andanswer' of 'modern scientific field-work' to 'penetrate to the exception, to the deviation, to the breach of custom,' which he argues can only be attained through language acquisition and prolonged residence among the people (1929:425-429).

14. Interview notes, Liluta village, 11/10/03.

15. Interview notes, Mulosaida village, 16/10/03.

16. Taped group discussion with women of mixed age and marital status, Orabesi village, $6 / 6 / 03$

17. Taped interview with married woman, aged mid-30s, Mulosaida village, 14/01/01.

18. Interview notes, Losuia Health Centre, 10/12/03.

19. The supply of condoms in the Trobriands is irregular and insufficient to meet demand. The Village Birth Attendants (VBA) program, established in the early 1990 s, provides the main condom distribution network. with generic male condoms supplied free of charge through the district health centre. The VBA program involves over one hundred women volunteers who have received basic training in clinical birthing procedures and reproductive health matters, including HIV and AIDS awareness.

20. Taped group discussion, Kaituvi village, 19/9/03.

21. Taped group discussion with women of mixed age and marital status, Orabesi village, 6/6/03

\section{REFERENCES}

BLACK, R H. 1957. Dr. Bellamy of Papua. The Medical Journal of Australia 2:279-84.

BUJRA, J. 2000. Risk and Trust: Unsafe Sex, Gender and AIDS in Tanzania. In Patricia Caplan (ed.), Risk Revisited, pp. 59-84. London: Pluto Press.

CRADDOCK, S. 2000. Disease, Social Identity, and Risk: Rethinking the Geography of AIDS. Transactions of the Institute of British Geographers 25:153-68.

DENOON, D. with K. DUGAN and L. MARSHALL. 1989. Public Health in Papua New Guinea: Medical Possibility and Social Constraint, 1884-1984. Cambridge, New York: Cambridge University Press. 
EVES, R. 2003. AIDS and Apocalypticism: Interpretations of the Epidemic from Papua New Guinea. Culture, Health \& Sexuality 5(3):249-64.

1996. Colonialism, Corporeality and Character: Methodist Missions and the Refashioning of Bodies in the Pacific. History and Anthropology 10(1):85-138.

FARMER, P. 1990. Sending Sickness: Sorcery, Politics, and Changing Concepts of AIDS in Rural Haiti. Medical Anthropology Quarterly, New Series, Culture and Behaviour in the AIDS Epidemic 4(1):6-27.

1992. New Disonder, Old Dilemmas: AIDS and Anthropology in Haiti. In Gilbert Hendt and Shirley Lindenbaum (eds), The Time of AIDS: Social Analysis, Theory, and Method, pp. 287-318. Newbury Park: Sage Publications. FOSTER, G. M. 1976. Disease Etiologies in Non-Western Medical Systems. American Anthropologist 78(4):773-82.

HAMMAR, L. 2005. Fear and Loathing in Papua New Guinea: Sexual Behaviour and Sexual Health amidst AIDS Anxiety.' Unpublished paper presented at the Annual Meeting of the Association for Social Anthropology in Oceania, Kaua'i, Hawai'i, 2-5 February 2005.

1998. Sex Industries and Sexual Networking in Papua New Guinea: Public Health Risks and Implications. Pacific Health Dialog 5(1): 47-53.

HUBER, J. T. and M. L. GILLAPSY. 1998. Social Constructs and Disease: Implications for a Controlled Vocabulary for HIV/AIDS. Library Trends 47(2): 190-208.

HUGHES, J. 1997. A History of Sexually Transmitted Diseases in Papua New Guinea. In M. Lewis, S. Bamber, and M. Waugh (eds), Sex, Disease, and Society: A Comparative History of Sexually Transmitted Diseases and HIV/AIDS in Asia and the Pacific, pp. 231-48. Westport, Connecticut: Greenwood Press.

INGSTAD, B. 1990. The Cultural Construction of AIDS and its Consequences for Prevention in Botswana. Medical Anthropology Quarterly, New Series, 4(1):28-40.

JOLLY, M. 1992. Banana Leaf Bundles and Skirts: A Pacific Penelope's Web? In J. G. Carrier (ed.), History and Tradition in Melanesian Anthropology, pp. 38-63. Berkeley: University of California Press.

LAWTON, R. 1993. Topics in the Description of Kiriwina. Pacific Linguistics Series D-84. Canberra: Department of Linguistics, Research School of Pacific Studies, Australian National University.

LEPANI, K. 2001. Negotiating 'Open Space': The Importance of Cultural Context in HIV/AIDS Communication Models. A Qualitative Study of Gender, Sexuality, and Reproduction in the Trobriand Islands of Papua New Guinea. Master of Public Health (Tropical Health) thesis, School of Population Health, The University of Queensland.

LEWIS. G. 1993. Double Standards of Treatment Evaluation. In S. Lindenbaum and M. Lock (eds), Knowledge, Power, and Practice: The Anthropology of Medicine and Everyday Life, pp. 189-218. Berkeley: University of California Press.

LUKER, V. 2004. Civil Society, Social Capital and the Churches: HIV/AIDS in Papua New Guinea. State, Society and Governance in Melanesia Project Working Paper 1/2004. Electronic document, accessed March 31, 2005. http://rspas.anu.edu.au/melanesia/working.php

MACINTYRE, M. 1987. Flying Witches and Leaping Warriors: Supernatural Origins of Power and Matrilineal Authority in Tubetube Society. In M. Strathern (ed.), Dealing with Inequality: Analysing Gender Relations in Melanesia and Beyond, pp. 207-29. Cambridge and New York: Cambridge University Press.

MALINOWSKI, B. 1929. The Sexual Lives of Savages in North-Western Melanesia: An Ethnographic Account of Courtship, Marriage and Family Life among the Natives of the Trobriand Islands, British New Guinea. Third Edition (1932), New York: Harcourt, Brace \& World.

1953. Sex and Repression in Savage Society, $4^{\text {th }}$ Edition. London: Routledge \& Kegan Paul Ltd.

MEIGS, A., and K. BARLOW. 2002. Beyond the Taboo: Imagining Incest. American Anthropologist 104(1):38-49.

PELTO, P. J., and G. H. PELTO. 1997. Studying Knowledge, Culture, and Behaviour in Applied Medical Anthropology. Medical Anthropology Quarterly 11(2):147-163.

REED, A. 1997. Contested Images and Common Strategies: Early Colonial Sexual Politics in the Massim. In Lenore Manderson and Margaret Jolly (eds), Sites of Desire, Economies of Pleasure: Sexualities in Asia and the Pacific, pp. 48-71. Chicago: University of Chicago Press.

REID, E. 1994. Approaching the Epidemic. Issues paper No. 14. HIV and Development Programme. New York: United Nations Development Programme.

SETEL, P. W. 1999. A Plague of Paradoxes: AIDS, Culture and Demography in Northern Tanzania. Chicago \& London: The University of Chicago Press.

SOBO, E. J. 1993. Bodies, Kin, and Flow: Family Planning in Rural Jamaica. Medical Anthropology Quarterly 7(1):50-73.

TAYLOR, C. 1988. The Concept of Flow in Rwandan Popular Medicine. Social Science and Medicine 27:1343-48.

TREICHLER, P. A. 1999. AIDS. Homophobia, and Biomedical Discourse: An Epidemic of Signification. In P. A. Treichler, How to Have Theory in an Epidemic: Cultural Chronicles of AIDS, pp. 11-41. Durham and London: Duke University Press.

WEINER, A. B. 1976. Women of Value, Men of Renown. Austin: University of Texas Press.

1979. Trobriand Kinship from another View: The Reproductive Power of Women. Man 14(2):328-48.

1980a. Reproduction: A Replacement for Reciprocity. American Ethnologist 7:71-85.

1980b. Stability in Banana Leaves: Colonialism, Economics and Trobriand Women. In M. Etienne and E. Leacock (eds), Women and Colonization: Anthropological Perspectives, pp. 270-93. New York: J.F. Bergin.

1988. The Trobrianders of Papua New Guinea. New York: Holt, Rinehart and Winston.

1992. Inalienable Possessions: The Paradox of Keeping-While-Giving. Berkeley: University of California Press. 